\title{
Risk Factors of Pulmonary Hypertension in Patients on Hemodialysis: A Single Center Study
}

\author{
Shankar Prasad Nagaraju' \\ Mohan V Bhojaraja $\mathbb{I}^{\prime}$ \\ Ganesh Paramasivam ${ }^{2}$ \\ Ravindra Attur Prabhu' \\ Dharshan Rangaswamy' \\ Indu Ramachandra Rao' \\ Srinivas Vinayak Shenoy (D) \\ 'Department of Nephrology, Kasturba \\ Medical College, Manipal, Manipal \\ Academy Higher Education, Manipal, \\ Karnataka, 576104, India; ${ }^{2}$ Department of \\ Cardiology, Kasturba Medical College, \\ Manipal, Manipal Academy Higher \\ Education, Manipal, Karnataka, 576104, \\ India
}

Introduction: Pulmonary hypertension $(\mathrm{PH})$ is an underestimated cardiovascular consequence and a mortality predictor in patients on hemodialysis (HD). Thus, we studied its prevalence, risk factors, association with inflammation/oxidative stress, and cardiac changes in HD patients.

Methods: This was a single-center cross-sectional observational study conducted at a tertiary care hospital. Patients aged $>18$ years on hemodialysis for at least three months were included and divided into those with and without $\mathrm{PH}$; patients with secondary causes for $\mathrm{PH}$ were excluded. Clinical characteristics, HD-related factors, lab parameters (C-reactive protein and malondialdehyde with thiol assay were used as markers of inflammation and oxidative stress, respectively), and echocardiography details were compared. $\mathrm{PH}$ was defined as a mean pulmonary artery pressure of $>25 \mathrm{mmHg}$ at rest, and it was further divided as mild $(25-40 \mathrm{mmHg})$, moderate $(40-60 \mathrm{mmHg})$, and severe ( $>60 \mathrm{mmHg}$ ).

Results: Of 52 patients, 28 patients had PH (mild 24, moderate 4, and none had severe $\mathrm{PH}$ ) with prevalence of $54 \%$. No difference was found in clinical characteristics, dialysis-related factors, biochemical parameters including inflammation (C-reactive protein; $p=0.76$ ), or oxidative stress (thiol; $p=0.36$ and MDA; $p=0.46$ ) between the groups. When compared to individuals without $\mathrm{PH}$, HD patients with $\mathrm{PH}$ exhibited significantly more mitral regurgitation $(p=0.002)$.

Conclusion: Hemodialysis patients have a high prevalence of $\mathrm{PH}$. PH was significantly associated with the presence of mitral regurgitation on echocardiography. Our study did not find differences in traditional risk factors, HD-related factors, and inflammation/oxidative markers between the groups with and without PH.

Keywords: chronic kidney disease, hemodialysis, inflammation, oxidative stress, pulmonary hypertension

\section{Introduction}

Pulmonary hypertension (PH) is exceedingly prevalent in both pre-dialysis and dialysis-dependent populations but is often overlooked and underestimated. Endothelial dysfunction and remodeling of the medial and intimal layers of the pulmonary vasculature characterize $\mathrm{PH}$, resulting in constrictive and occlusive vascular lesions. ${ }^{1}$

$\mathrm{PH}$ in patients on any kind of dialysis have a median prevalence of $38 \%$ (8$70 \%), 40 \%(16-70 \%)$ on hemodialysis (HD), and 19\% (8-37\%) on peritoneal dialysis (PD). ${ }^{2}$ Pulmonary hypertension is linked to an increased risk of death and cardiovascular events in CKD patients. End stage renal disease (ESRD) patients on dialysis have a higher risk than patients with CKD stages 1 to $5 .^{3}$
Correspondence: Mohan V Bhojaraja Email mohan.vb@manipal.edu 
The normal pulmonary artery pressure is $14 \pm 3 \mathrm{mmHg}$, with a maximum of $20 \mathrm{mmHg}$, while resting mean pulmonary artery pressure of $>25 \mathrm{mmHg}$ is considered $\mathrm{PH}$. $\mathrm{PH}$ in patients with chronic renal failure is classified as "category 5: PH with unknown multifactorial etiology" by the World Health Organization (WHO). ${ }^{4}$

The risk factors and causes for $\mathrm{PH}$ in $\mathrm{HD}$ patients remain unknown and have not been addressed specifically. Previous research has revealed that age, type of arteriovenous fistula (AVF), bone mineral abnormalities, length of HD, fluid overload condition, and systolic and diastolic dysfunction may all play a role, ${ }^{5-9}$ but these risk factors vary with each study and definitive factors for the development of PH are yet to be identified.

The AVF influence on development of PH in hemodialysis patients depend upon the type of AVF, duration of usage, and blood flow rates across the AVF. This is probably due to increased cardiac output (CO) causing elevated pulmonary artery pressures, however the association is yet to be established. ${ }^{10-16}$

Oxidative stress and inflammation are highly prevalent in the hemodialysis population. Increased oxidant activity and decreased antioxidant ability causes excessive oxidative stress and factors such as malnutrition, chronic volume overload, and autonomic dysfunction lead to a persistent inflammatory state. Both oxidative stress as well as persistent inflammation eventually causes endothelial dysfunction which contributes to the development of cardiac dysfunction. However, the role of oxidative stress and inflammation in the development of PH is yet to be fully established. ${ }^{7}$

As a result, this cross-sectional study was undertaken in hemodialysis patients to determine the prevalence and risk factors associated with $\mathrm{PH}$, its association with inflammation/oxidative stress, and structural as well as functional cardiac changes.

\section{Materials and Methods}

A single-center cross-sectional study was conducted in the dialysis unit, Department of Nephrology at Kasturba Medical College, Manipal from June 2016 to May 2017. The study protocol conforms to the ethical guidelines of the 1975 Declaration of Helsinki as reflected in a priori approval by the institution's human research committee. The study protocol was approved by the institutional ethics committee of Kasturba Medical College, Manipal Academy of Higher Education. Accordingly, informed consent was obtained from each patient enrolled in the study.

\section{Inclusion Criteria}

- All chronic kidney disease patients aged above 18 years on maintenance hemodialysis for at least three months were included.

\section{Exclusion Criteria}

- Those with valvular heart disease, pulmonary obstructive and restrictive diseases, congenital heart diseases, connective tissue diseases, HIV infection, chronic pulmonary thromboembolism, obstructive sleep apnea, chronic liver disease, hypothyroidism, and hyperthyroidism were excluded.

The baseline demographic, biochemical, and clinical data were collected for all patients. The patients were categorized into two groups based on the presence or absence of $\mathrm{PH}$. These two groups were compared for:

1. Clinical characteristics which included age, gender, etiology of end stage renal disease (ESRD), presence of hypertension, cerebrovascular accident, smoking, and ischemic heart disease.

2. Dialysis-related factors such as presence of arteriovenous fistula (AVF), AVF flow rates, dialysis vintage, residual urine output, volume status, and ultrafiltration rate per session.

3. Volume status assessment: volume status was assessed in all patients by standard clinical method as per KDIGO recommendation which included presence of peripheral edema, rise in jugular venous pressure, and blood pressure control by a single nephrologist. Ultrafiltration rate was estimated for each session and all were dialysed to reach their target dry weight.

4. AVF flow rate $(\mathrm{mL} / \mathrm{min})$ estimation was done by using Doppler ultrasonography with a $7 \mathrm{MHz}$ linear probe using the cross-sectional area $\left(\mathrm{cm}^{2}\right)$ and the mean velocity $(\mathrm{cm} / \mathrm{s})$.

5. Lab parameters such as hemoglobin, albumin, calcium, phosphorus, and parathormone (PTH).

6. Inflammatory and oxidative stress biomarkers: C-reactive protein (CRP), malondialdehyde (MDA), and thiol assay.

CRP, thiol, and MDA level estimation: pre-HD blood was collected in plain vacutainer tubes, plasma was immediately separated from blood by centrifugation at $1000 \times \mathrm{g}$ for 
$15 \mathrm{~min}$ at $4{ }^{\circ} \mathrm{C}$ and samples were stored at $-70{ }^{\circ} \mathrm{C}$ until usage. Biochemical analyses were done according to the following principles: CRP assay by immunoturbidimetric method, thiol (-SH) assay by Ellman's method [spectrophotometric method using dinitrobenzene (DTNB)], and MDA assay by Kei Satoh's method.

1. Structural and functional cardiac changes: electrocardiogram (ECG) and echocardiography (ECHO) were analyzed one hour post hemodialysis for all patients. The ECG was reviewed for features associated with $\mathrm{PH}$ such as right atrial (RA), right ventricular (RV) strain pattern, RV enlargement, left ventricular (LV) strain pattern, and wall motion abnormalities.

The Bernoulli equation was used to determine estimated pulmonary artery systolic pressure (ePASP) from tricuspid regurgitant velocity (TRV) and estimated right atrium (RA) pressure $\left[\mathrm{ePASP}=4(\mathrm{TRV})^{2}+\mathrm{RA}\right.$ pressure $]$. The inferior vena cava (IVC) diameter as well as collapse were used to determine whether the RA pressure was normal, moderate, or excessive $(3,8$, and $15 \mathrm{mmHg}$, respectively). Further, the mean pulmonary artery pressure (mPAP) was calculated from ePASP using a standard formula $(\mathrm{mPAP}=0.61(\mathrm{ePASP})+2 \mathrm{mmHg}){ }^{17,18}$

At rest, $\mathrm{PH}$ was defined as an estimated mPAP of more than $25 \mathrm{mmHg}$. Mild PH (mPAP $>25$ up to $40 \mathrm{mmHg}$ ), moderate $\mathrm{PH}$ (mPAP $>40$ up to $60 \mathrm{mmHg}$ ), and severe $\mathrm{PH}$ (mPAP $>60 \mathrm{mmHg}$ ) were all classified. ${ }^{19}$

Other parameters compared between the two groups were LV ejection fraction, mitral regurgitation (MR), presence of left ventricular hypertrophy $(\mathrm{LVH})$, regional wall motion abnormality (RWMA), left ventricular systolic dysfunction (LVSD), right ventricular systolic dysfunction (RVSD), and left ventricular diastolic dysfunction (LVDD).

\section{Statistical Analysis}

All continuous variables which were regularly distributed used mean \pm standard deviation (SD) to characterize it and independent Student's $t$-tests was used to compare these variables between the non-PH and $\mathrm{PH}$ groups. The nonnormally distributed variables were reported as medians (25-75\%) and compared between the $\mathrm{PH}$ and non-PH groups using non-parametric testing. The significance of the results was determined at a $5 \%$ level of significance ( $p$-value $<0.05)$. The data were analyzed using the Statistical Package for the Social Sciences (SPSS) (version 20.0, IBM Corp. 2010, Armonk, NY, USA).

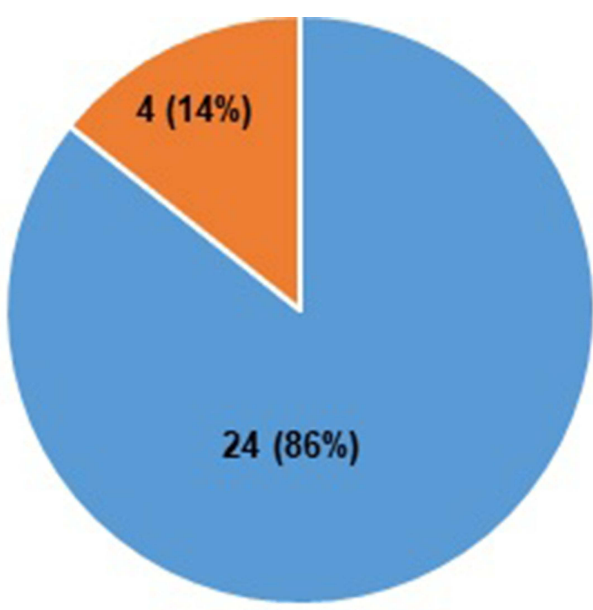

\section{- Mild PH $\quad$ Moderate PH}

Figure I Prevalence of $\mathrm{PH}$ in HD patients $(n=28)$.

\section{Results}

A total of 52 individuals were analyzed during the study period, among them 28 (54\%) had PH. The majority of HD patients had mild $\mathrm{PH}$, with 24 (85.7\%) showing mild $\mathrm{PH}, 4$ (14.3\%) showing moderate $\mathrm{PH}$, and none showing severe PH (Figure 1). Our population's average age was $54.86 \pm 9.2$ years, with the majority men (77\%).

On comparing the clinical features between patients with and without $\mathrm{PH}$, none of the clinical or dialysisrelated risk factors like age, gender, etiology of ESRD, presence of hypertension $(p=0.12)$, ischemic heart disease $(p=0.53)$, smoking, CVA, access type $(p=0.13)$, AVF flow rates, hypervolemia, dialysis vintage $(p=0.42)$, residual urine output $(p=0.32)$, and UF rate $(p=0.83)$ had any statistically significant impact on occurrence of $\mathrm{PH}$ (Table 1). Similarly, among laboratory parameters, anemia, hypoalbuminemia, hyperparathyroidism, and ferritin levels were not found to be risk factors in our hemodialysis population $(p>0.05)$ (Table 2$)$.

The presence of inflammation was assessed by doing CRP in our hemodialysis patients. The median CRP level was $2.0 \mathrm{mg} / \mathrm{L}$ in patients with $\mathrm{PH}$ and was $2.2 \mathrm{mg} / \mathrm{L}$ in patients without PH. It was not statistically significant $(p=0.76)$.

To see the severity of oxidative stress and its association with $\mathrm{PH}$ among our patients both thiol assay and malondialdehyde assay were done. The malondialdehyde levels were comparable between the groups $(p=0.46)$. Patients with $\mathrm{PH}$ had slightly higher median thiol levels (304 $\mu \mathrm{mol} / \mathrm{L})$ than those without PH $(223.9 \mu \mathrm{mol} / \mathrm{L})$ with 
Table I Clinical Characteristics and Dialysis Related Factors of HD Patients

\begin{tabular}{|c|c|c|c|c|}
\hline Characteristics & Total $(n=52)$ & With PH $(n=28)$ & Without PH $(n=24)$ & “p” value (<0.05 significant) \\
\hline Age (in years) ${ }^{\mathrm{a}}$ & $54.86 \pm 9.2$ & $56.5 \pm 9.3$ & $57.1 \pm 5.3$ & 0.31 \\
\hline Males & 40 (76.9\%) & $19(67.8 \%)$ & 21 (87.5\%) & 0.09 \\
\hline \multicolumn{5}{|l|}{ Etiology of ESRD: } \\
\hline Diabetes mellitus & $17(32.6 \%)$ & $10(35.7 \%)$ & 7 (29.1\%) & 0.61 \\
\hline Hypertension & 7 (I3.4\%) & $4(14.2 \%)$ & $3(12.5 \%)$ & 0.86 \\
\hline Glomerulonephritis & $15(28.8 \%)$ & 8 (28.5\%) & 7 (29.1\%) & 0.97 \\
\hline Interstitial & $6(11.5 \%)$ & $3(10.7 \%)$ & $3(12.5 \%)$ & 0.85 \\
\hline APKD & $3(5.7 \%)$ & $2(7.1 \%)$ & I (4.1\%) & 0.66 \\
\hline Other & $4(7.6 \%)$ & I (3.5\%) & $3(12.5 \%)$ & 0.26 \\
\hline Hypertension & 51 (98\%) & $28(100 \%)$ & $23(95.8 \%)$ & 0.12 \\
\hline Cerebrovascular accident & $2(3.8 \%)$ & I (3.5\%) & I (4.I\%) & 0.91 \\
\hline Ischemic heart disease & 7 (I3.4\%) & $3(10.7 \%)$ & $4(16.6 \%)$ & 0.53 \\
\hline Smoking & $2(3.8 \%)$ & I (3.5\%) & I (4.I\%) & 0.27 \\
\hline Arteriovenous fistula & $48(92.3 \%)$ & $26(92.8 \%)$ & 22 (91.6\%) & 0.13 \\
\hline AV fistula flow rates $(\mathrm{mL} / \mathrm{min})$ & & $754.5(572-1098)$ & $780(598-1168)$ & 0.37 \\
\hline Vintage on dialysis (in months) ${ }^{\mathrm{b}}$ & $36(22-91)$ & $30(22-84)$ & 47 (24-97) & 0.42 \\
\hline Residual urine $(<100 \mathrm{~mL})$ & $34(65.3 \%)$ & 20 (7I.4\%) & 14 (58.3\%) & 0.32 \\
\hline Hypervolemia by clinical method & 32 (6I.5\%) & 17 (60.5\%) & $15(62.5 \%)$ & 0.94 \\
\hline Ultrafiltration rate $(\mathrm{mL} / \mathrm{hour} / \mathrm{kg})^{\mathrm{b}}$ & $15(11-18)$ & $14(12-16)$ & $13(11-15)$ & 0.86 \\
\hline
\end{tabular}

Notes: a Mean; ${ }^{b}$ Median.

Table 2 Laboratory Parameters in HD Patients

\begin{tabular}{|c|c|c|c|c|}
\hline Parameters & Total $(n=52)$ & With PH $(n=28)$ & Without PH $(n=24)$ & “p” value (<0.05 significant) \\
\hline Hemoglobin $(g / L)^{a}$ & $9.7 \pm 0.9$ & $9.1 \pm 1.2$ & $10.2 \pm 0.6$ & 0.14 \\
\hline Calcium $(\mathrm{mg} / \mathrm{dl})^{\mathrm{a}}$ & $8.5 \pm 0.4$ & $8.7 \pm 0.5$ & $8.2 \pm 0.3$ & 0.16 \\
\hline Phosphorus (mg/dl) ${ }^{\mathrm{a}}$ & $4.4 \pm 1.1$ & $4.5 \pm 0.6$ & $4.7 \pm 1.7$ & 0.08 \\
\hline Albumin $(g / L)^{a}$ & $4.05 \pm 0.3$ & $4.1 \pm 0.2$ & $4 \pm 0.3$ & 0.12 \\
\hline PTH $(\mathrm{pg} / \mathrm{mL})^{\mathrm{b}}$ & $333(|75-56|)$ & $366(182-544)$ & $219.4(156-520)$ & 0.66 \\
\hline Serum ferritin $(m g)^{b}$ & $1214(990-|78|)$ & 1224 (1037-1987) & $1204(376-|68|)$ & 0.64 \\
\hline C-Reactive protein $(\mathrm{mg} / \mathrm{L})^{\mathrm{b}}$ & $2.1(1.3-5.3)$ & $2(1.3-5.8)$ & $2.2(1.5-4)$ & 0.76 \\
\hline Thiol $(\mu \mathrm{mol} / \mathrm{L})^{\mathrm{b}}$ & $266(182-605)$ & $304(146-776)$ & $223.9(|87-4| 7)$ & 0.36 \\
\hline Malondialdehyde $(\mu \mathrm{mol} / \mathrm{L})^{\mathrm{b}}$ & $0.199(0.174-0.226)$ & $0.198(0.178-0.221)$ & $0.202(0.174-0.234)$ & 0.46 \\
\hline
\end{tabular}

Notes: a Mean; ${ }^{\mathrm{b} M e d i a n .}$

no statistical significance $(p=0.36)$. In this study, both inflammatory markers and oxidative stress markers level were similar irrespective of presence of PH (Table 2).

Echocardiographic findings:
Ejection fraction (EF), RWMA, LVSD, LVH, RVSD, and LVDD were analysed without significant difference ( $p$-value $>0.05$ ) (Table 3). However, among 28 patients with $\mathrm{PH}, 23$ patients had mitral regurgitation whereas it was seen 
Table 3 Echocardiographic Findings in HD Patients

\begin{tabular}{|l|l|l|l|l|}
\hline Echocardiographic Findings & Total $(\mathbf{n = 5 2 )}$ & With PH (n= 28) & Without PH (n=24) & “p” value (<0.05 significant) \\
\hline EF (\%) & $63.5(57.7-66)$ & $62(53-65)$ & $65(62-67)$ & 0.31 \\
\hline LVH & $37(71.1 \%)$ & $18(64.2 \%)$ & $19(79.1 \%)$ & 0.49 \\
\hline RWMA & $7(13.4 \%)$ & $4(14.2 \%)$ & $3(12.5 \%)$ & 0.63 \\
\hline MR ${ }^{\text {b }}$ & $32(61.5 \%)$ & $23(82.1 \%)$ & $9(37.5 \%)$ & 0.002 \\
\hline LVSD & $9(17.3 \%)$ & $8(28.5 \%)$ & $1(4.1 \%)$ & 0.09 \\
\hline LVDD & $13(25 \%)$ & $8(28.5 \%)$ & $5(20.8 \%)$ & 0.58 \\
\hline RVSD & $4(7.6 \%)$ & $4(14.2 \%)$ & 0 & 0.07 \\
\hline
\end{tabular}

Notes: "Median; " "p" value $<0.05$ significant.

Abbreviations: EF, ejection fraction; LVH, left ventricular hypertrophy; RWMA, regional wall motion abnormality; MR, mitral regurgitation; LVSD, left ventricular systolic dysfunction; LVDD, left ventricular diastolic dysfunction; RVSD, right ventricular systolic dysfunction.

only among 9 patients without $\mathrm{PH}$, thus a statistically significant difference was noted $(p=0.002$ ) (Table 3 ).

\section{Discussion}

The prevalence of $\mathrm{PH}$ in hemodialysis is high and varies from 20 to $70 \%$. In the present study it was $54 \%$ with the majority having mild PH. This is similar to prior Western and Indian studies wherein the prevalence varies from 16 to $70 \%$. The reason for such heterogeneity in the prevalence of $\mathrm{PH}$ is attributed to the variation in population ethnicity, comorbid conditions, and inclusion criteria of the prior studies. Despite the fact that these studies used different criteria and are not truly equivalent, the majority of them found a greater prevalence of $\mathrm{PH}$ in $\mathrm{HD}$ patients. ${ }^{2,5,6,8,9}$

$\mathrm{PH}$ in patients with renal dysfunction is multifactorial with specific risk factors being unclear. The overall pathogenesis of PH remains poorly understood and is attributed to various risk factors like underlying patient's age, presence of cardiac dysfunction, vintage on dialysis, presence of an arteriovenous fistula, exposure to dialyzer membranes, chronic fluid overload state, persistent anemia, untreated bone mineral disorder, uremic toxins, and uremic vasculopathy. ${ }^{5}$

In this study, the mean age of HD patients with $\mathrm{PH}$ was $56.5 \pm 9.3$ years and the majority were males with no significant effect found between age as well as gender on prevalence of PH. Studies by Mazdeh et al ( $\mathrm{n}=62 ; p-0.58)$ ${ }^{20}$ and Patel et al $(\mathrm{n}=100 ; p-0.402)^{21}$ showed similar results wherein there was no association between age and $\mathrm{PH}$.
The study by Tarras et al $(n=200 ; p-0.37)^{22}$ was similar to this study wherein no effect of gender on $\mathrm{PH}$ prevalence was observed.

Also, there was no statistically significant association found between other proposed risk factors like diabetes, hypertension, smoking, CVA, and IHD with prevalence of $\mathrm{PH}$ in our study. It is similar to the results seen in the retrospective analysis by Zhang et al $(n=170){ }^{8}$

In literature, the hemodynamic impact of AVF in hemodialysis patients is yet to be established. While the majority of authors believe that there are links between the vintage of hemodialysis (via AVF) and the development of $\mathrm{PH},{ }^{10-12}$ there are differing views on the involvement of AVF in the occurrence of PH. In a small prospective research of 12 patients, Yigla et al ${ }^{13}$ showed the influence of increasing cardiac output (CO) after AVF creation on the rise of pulmonary arterial pressure (PAP). Afzal et al ${ }^{11}$ mentioned in a recent article that among the factors contributing to the development of PH, AVF could be one of the causes of unexplained elevated PAP. Other researchers, on the other hand, discovered no link between AVF flow rates and development of $\mathrm{PH}$ similar to our finding. ${ }^{14}$ The majority of evidence suggests that the establishment of AVF is not the key determinant of the development of $\mathrm{PH}$ in individuals with ESRD. ${ }^{15,16}$

In the study by Mehta et al, ${ }^{6}$ higher prevalence of $\mathrm{PH}$ was seen in patients who had longer dialysis 
vintage $(p<0.001)$ and the study by Pabst et al $(\mathrm{n}=62)^{23}$ showed reduction in prevalence of $\mathrm{PH}$ immediately post dialysis which was attributed to ultrafiltration. However, in our study dialysis-related factors were similar between the groups. None of the laboratory risk factors like anemia, serum calcium, phosphorus, albumin, PTH, and ferritin were found to be significantly associated with $\mathrm{PH}$ which is similar to previous studies. ${ }^{8,9}$

This study did not reveal any significant association with inflammation (CRP levels) and oxidative stress (MDA and thiol assay) in our hemodialysis patients. This is unlike the recent study by Sonkar et al $(n=82)^{7}$ wherein a higher level of inflammatory marker (alpha1-acid glycoprotein) was seen in HD patients with $\mathrm{PH}$. Another study by Smukowska-Gorynia et $\mathrm{al}^{24}$ revealed higher levels of MDA in patients with $\mathrm{PH}$ but it included non-CKD and non-HD-dependent patients. This may be due to different populations and the various markers used in different studies. The disparity in the results highlights the need for further studies to establish the role of oxidative stress and inflammation in the development of $\mathrm{PH}$ in hemodialysis patients. In this study, few echocardiographic findings were significantly different between patients with and without $\mathrm{PH}$. Among them, although left and right ventricular dysfunction were strikingly noted in patients with $\mathrm{PH}$, these were not statistically significant. This is similar to studies by Agarwal ${ }^{1}$ and Ramasubbu et $\mathrm{al}^{25}$ which revealed a multifactorial mechanism induced by elevated mean arterial pressure, anemia-mediated hypoxemic stress, uremia induced cardiac myocyte dysregulation, chronic volume overload, and impairment of cardiac function by microvascular and macrovascular coronary artery disease, all of which causes subclinical left and right ventricular dysfunction thus contributing to increased pulmonary capillary wedge pressure and ultimately leading to $\mathrm{PH}$.

However, among patients with and without $\mathrm{PH}$, there was a statistically significant difference in the occurrence of mitral regurgitation in our study. This is similar to a study by Yigla et al, ${ }^{26}$ in which $37 / 127$ patients had $\mathrm{PH}$, and those with $\mathrm{PH}$ had a significantly higher prevalence of mitral regurgitation ( $54 \%$ vs $13 \%$ in those without $\mathrm{PH}$ ), as well as a higher prevalence of
LV systolic dysfunction. Also, the study by Cirit et al $(n=56)^{27}$ found that in patients on both HD and PD, $100 \%$ of those with $\mathrm{PH}$ had mitral valve insufficiency, compared to $79 \%$ of those without PH. The most common cause of pulmonary hypertension is left heart disease. Patients with CKD are known to have LV systolic and diastolic dysfunction (overt or subclinical), LV hypertrophy, and LV dilation along with elevated LV end-diastolic pressures. Secondary mitral regurgitation of various degrees are seen caused by the above mentioned changes in LV structure and function. Longstanding elevated LVEDP is known to be a key factor in the development of pulmonary hypertension. Therefore, secondary mitral regurgitation and pulmonary hypertension in patients with CKD share common underlying causes. The strong association seen between pulmonary hypertension and mitral regurgitation in our study can be explained by this common underlying pathophysiology. ${ }^{28}$

PH in CKD can occur through multiple mechanisms as discussed earlier. In our study, other than the presence of significant mitral regurgitation in HD patients with $\mathrm{PH}$, none of the other factors were found significant. Previous studies though identified few other risk factors, there is no uniformity and risk factors vary with each study as summarized in Table 4.

\section{Limitations}

The cross-sectional design of our study prevents the establishment of a temporal relationship. Limited by small sample size and diagnosis of $\mathrm{PH}$ was not established by right heart catheterization. Volume status assessment was performed by standard clinical methods instead of objective assessment using bioimpedance or by inferior vena cava diameter and collapsibility.

\section{Conclusion}

HD patients have a higher prevalence of PH. Presence of traditional risk factors, dialysis-related factors, anemia, components of CKD-MBD, and inflammation/oxidative stress did not influence the prevalence of $\mathrm{PH}$ in our HD population. HD patients with $\mathrm{PH}$ have both left and right systolic dysfunction and it is significantly associated with the presence of mitral regurgitation. 
Table 4 Comparing with Other Studies in HD Patients with $\mathrm{PH}$

\begin{tabular}{|c|c|c|c|c|c|}
\hline $\begin{array}{l}\text { Author and Year of } \\
\text { Publication }\end{array}$ & $\begin{array}{l}\text { Type of } \\
\text { Study }\end{array}$ & $\begin{array}{l}\text { Mean Age } \\
\text { (Years) }\end{array}$ & $\begin{array}{l}\text { HD Patients } \\
\text { with PH }\end{array}$ & PH Prevalence & Risk Factors Identified in the Study \\
\hline Our study & $\begin{array}{l}\text { Cross- } \\
\text { sectional } \\
\text { study }\end{array}$ & $54.86 \pm 9.2$ & $n=28$ & $54 \%$ & $\begin{array}{l}\text { Significant mitral regurgitation was observed in HD } \\
\text { patients with PH }\end{array}$ \\
\hline Sonkar et al $2020^{7}$ & $\begin{array}{l}\text { Cross- } \\
\text { sectional } \\
\text { study }\end{array}$ & $43.48 \pm 14.65$ & $n=82$ & $25.6 \%$ & $\begin{array}{l}\text { Inflammatory indicators were higher and ejection fraction } \\
\text { decreased }\end{array}$ \\
\hline Zhang et al $2020^{8}$ & $\begin{array}{l}\text { Retrospective } \\
\text { study }\end{array}$ & $52.95 \pm \mid 4.21$ & $n=491$ & $34.6 \%$ & Left and right atria sizes as well as $L V$ ejection fraction \\
\hline Engole et al $2020^{29}$ & $\begin{array}{l}\text { Cross- } \\
\text { sectional } \\
\text { study }\end{array}$ & $52.6 \pm 15.9$ & $n=85$ & $29.4 \%$ & $\begin{array}{l}\text { Vascular access change, arrhythmia, and diastolic } \\
\text { dysfunction }\end{array}$ \\
\hline Nithiya et al $2020^{9}$ & $\begin{array}{l}\text { Prospective } \\
\text { study }\end{array}$ & $47.5 \pm 13.7$ & $n=57$ & $48.7 \%$ & Increased left atrial diameter \\
\hline Mehta et al $2019^{6}$ & $\begin{array}{l}\text { Prospective } \\
\text { study }\end{array}$ & $47.85 \pm 13.09$ & $n=88$ & $\begin{array}{l}<6 \text { months on } \\
\text { HD: } 2.7 \% \text {; } \\
6-12 \text { months on } \\
\text { HD: } 43 \% \text {; } \\
>12 \text { months on } \\
\text { HD: } 54.1 \%\end{array}$ & $\begin{array}{l}\text { Increased dialysis vintage and patients with arteriovenous } \\
\text { fistula }\end{array}$ \\
\hline Singh et al $2018^{30}$ & $\begin{array}{l}\text { Cross- } \\
\text { sectional } \\
\text { study }\end{array}$ & 47.2 & $n=50$ & $34 \%$ & LV end diastolic pressure and mean ejection fractions \\
\hline Arun et al $2018^{5}$ & $\begin{array}{l}\text { Cross- } \\
\text { sectional } \\
\text { study }\end{array}$ & $43.53 \pm 14.63$ & $n=108$ & $\begin{array}{l}\text { On } 3 / 7 \text { HD: } \\
42.1 \% \\
\text { On } 2 / 7 \text { HD: } 45 \%\end{array}$ & $\begin{array}{l}\text { Anemia, higher interdialytic weight gain, LV systolic } \\
\text { dysfunction, LV diastolic dysfunction }\end{array}$ \\
\hline Fabbian et al $2010^{10}$ & $\begin{array}{l}\text { Prospective } \\
\text { study }\end{array}$ & $60 \pm 13$ & $n=29$ & $58.6 \%$ & Diabetes, increased dialysis vintage \\
\hline Yigla et al $2003^{31}$ & $\begin{array}{l}\text { Prospective } \\
\text { study }\end{array}$ & $58.8 \pm 15.7$ & $n=58$ & 39.7 & Anemia, patients with arteriovenous fistula \\
\hline
\end{tabular}

\section{Acknowledgments}

The abstract of this paper was presented at the 57th European Renal Association - European Dialysis and Transplant Association (ERA-EDTA) virtual 2020 congress as a poster presentation with interim findings. The poster's abstract was published in "Poster Abstracts" in Nephrology Dialysis Transplantation (https://doi.org/10. 1093/ndt/gfaa142.P1310).

\section{Funding}

There is no funding to report.

\section{Disclosure}

The authors report no conflicts of interest in this work.

\section{References}

1. Agarwal R. Prevalence, determinants and prognosis of pulmonary hypertension among hemodialysis patients. Nephrol Dial Transplant. 2012;27(10):3908-3914. doi:10.1093/ndt/gfr661

2. Schoenberg NC, Argula RG, Klings ES, Wilson KC, Farber HW. Prevalence and mortality of pulmonary hypertension in ESRD: a systematic review and meta-analysis. Lung. 2020;198(3):535-545. doi:10.1007/s00408-020-00355-0

3. Tang M, Batty JA, Lin C, Fan X, Chan KE, Kalim S. Pulmonary hypertension, mortality, and cardiovascular disease in CKD and ESRD patients: a systematic review and meta-analysis. Am J Kidney Dis. 2018;72(1):75-83. doi:10.1053/j.ajkd.2017.11.018

4. Simonneau G, Robbins IM, Beghetti M, et al. Updated clinical classification of pulmonary hypertension. $J$ Am Coll Cardiol. 2009;54(1S): S43-54. doi:10.1016/j.jacc.2009.04.012

5. Arun B, Suresh H, Moger V, Vijayalaxmi P, Mohan K. A prospective study of pulmonary hypertension in patients with chronic kidney disease: a new and pernicious complication. Indian J Nephrol. 2017. doi:10.4103/ijn.IJN_36_17 
6. Mehta KS, Shirkande AK, Bhurke SP, Pajai AE, Swami RS, Jadhav SN. Pulmonary hypertension in various stages of chronic kidney disease in Indian patients. Indian J Nephrol. 2019;29(2):95. doi:10.4103/ijn.IJN_407_17

7. Sonkar SK, Alam M, Chandra S, Sonkar GK, Gaikwad A, Bhosale V. Association of pulmonary hypertension with inflammatory markers and volume status in hemodialysis patients of end-stage renal disease. Cureus. 2021;13(3). doi:10.7759/cureus.13635

8. Zhang Y, Ding XH, Rao R, et al. The prevalence of pulmonary hypertension among maintenance dialysis patients with ESRD and its associated factors: a retrospective study. Front Med. 2020;4 (7):884.

9. Nithiya N, Indhumathi E, Jagadeswaran D, Jayaprakash V, Jayakumar M. Pulmonary hypertension-prevalence, risk factors, and its association with vascular calcification in chronic kidney disease and hemodialysis patients. Saudi J Kidney Dis Transpl. 2020;31 (2):380. doi:10.4103/1319-2442.284012

10. Afzal A, Bhatti MA, Manzoor S. Pulmonary hypertension: an emerging problem in patients undergoing regular hemodialysis. $J$ Coll Physicians Surg Pak. 2018;28(8):594-597. doi:10.29271/ jcpsp.2018.08.594

11. Tudoran M, Ciocarlie T, Mates A, Pescariu SA, AbuAwwad A, Tudoran C. Pulmonary hypertension in patients with end stage renal disease undergoing hemodialysis. Niger J Clin Pract. 2020;23 (2):198. doi:10.4103/njcp.njcp_278_19

12. Yigla M, Banderski R, Azzam ZS, Reisner SA, Nakhoul F. Arteriovenous access in end-stage renal disease patients and pulmonary hypertension. Ther Adv Respir Dis. 2008;2(2):49-53. doi:10.1177/ 1753465808089456

13. Acarturk G, Albayrak R, Melek M, et al. The relationship between arteriovenous fistula blood flow rate and pulmonary artery pressure in hemodialysis patients. Int Urol Nephrol. 2008;40(2):509-513. doi:10.1007/s11255-007-9269-8

14. Kawar B, Ellam T, Jackson C, Kiely DG. Pulmonary hypertension in renal disease: epidemiology, potential mechanisms and implications. Am J Nephrol. 2013;37(3):281-290. doi:10.1159/000348804

15. Sise ME, Courtwright AM, Channick RN. Pulmonary hypertension in patients with chronic and end-stage kidney disease. Kidney Int. 2013;84(4):682-692. doi:10.1038/ki.2013.186

16. Bossone E, D'Andrea A, D'Alto M, et al. Echocardiography in pulmonary arterial hypertension: from diagnosis to prognosis. $\mathrm{J} \mathrm{Am}$ Soc Echocardiogr. 2013;26(1):1-4. doi:10.1016/j.echo.2012.10.009

17. Chemla D, Castelain V, Humbert M, et al. New formula for predicting mean pulmonary artery pressure using systolic pulmonary artery pressure. Chest. 2004;126(4):1313-1317. doi:10.1378/chest.1 26.4.1313

18. Simonneau G, Montani D, Celermajer DS, et al. Haemodynamic definitions and updated clinical classification of pulmonary hypertension. Eur Respir J. 2019;53(1):1801913. doi:10.1183/ 13993003.01913-2018
19. Mahdavi-Mazdeh M, Alijavad-Mousavi S, Yahyazadeh H, Azadi M, Yoosefnejad H, Ataiipoor Y. Pulmonary hypertension in hemodialysis patients. Saudi J Kidney Dis Transpl. 2008;19(2):189.

20. Patel P, Abraham G, Pratap B, et al. Clinical and biochemical parameters in chronic kidney disease with pulmonary hypertension. Indian J Nephrol. 2007;17(1):4. doi:10.4103/0971-4065.35012

21. Tarrass F, Benjelloun M, Hachim K, Benghanem MG, Ramdani B. Pulmonary hypertension in patients with end-stage renal disease. Indian J Nephrol. 2005;15:223-226.

22. Pabst S, Hammerstingl C, Hundt F, et al. Pulmonary hypertension in patients with chronic kidney disease on dialysis and without dialysis: results of the PEPPER-study. PLoS One. 2012;7(4):e35310. doi:10.1371/journal.pone.0035310

23. Smukowska-Gorynia A, Rzymski P, Marcinkowska J, et al. Prognostic value of oxidative stress markers in patients with pulmonary arterial or chronic thromboembolic pulmonary hypertension. Oxid Med Cell Longev. 2019;2019:1-10. doi:10.1155/2019/3795320

24. Ramasubbu K, Deswal A, Herdejurgen C, Aguilar D, Frost AE. A prospective echocardiographic evaluation of pulmonary hypertension in chronic hemodialysis patients in the United States: prevalence and clinical significance. Int J Gen Med. 2010;3:279. doi:10.2147/ IJGM.S12946

25. Yigla M, Fruchter O, Aharonson D, et al. Pulmonary hypertension is an independent predictor of mortality in hemodialysis patients. Kidney Int. 2009;75(9):969-975. doi:10.1038/ki.2009.10

26. Cirit M, Ozkahya M, Cinar CS, et al. Disappearance of mitral and tricuspid regurgitation in haemodialysis patients after ultrafiltration. Nephrol Dial Transplant. 1998;13(2):389-392. doi:10.1093/oxfordjournals.ndt.a027835

27. Kiefer TL, Bashore TM. Pulmonary hypertension related to left-sided cardiac pathology. Pulm Med. 2011;2011:1-11. doi:10.1155/2011/ 381787

28. Engole YM, Lepira FB, Nlandu YM, et al. Prevalence and factors associated with pulmonary arterial hypertension on maintenance hemodialysis patients in Kinshasa, Democratic Republic of Congo: a cross-sectional study. BMC Nephrol. 2020;21(1):1-8. doi:10.1186/ s12882-020-02131-x

29. Singh NP, Nautiyal A, Karol A, Aggarwal NP, Minocha G, Gupta AK. Pulmonary hypertension in patients with end stage renal disease on maintenance hemodialysis: a cross-sectional study. J Assoc Physicians India. 2018;66(12):26-29.

30. Fabbian F, Cantelli S, Molino C, Pala M, Longhini C, Portaluppi F. Pulmonary hypertension in dialysis patients: a cross-sectional Italian study. Int J Nephrol. 2010;30:2011.

31. Yigla M, Nakhoul F, Sabag A, et al. Pulmonary hypertension in patients with end-stage renal disease. Chest. 2003;123 (5):1577-1582. doi:10.1378/chest.123.5.1577
The International Journal of Nephrology and Renovascular Disease is an international, peer-reviewed open-access journal focusing on the pathophysiology of the kidney and vascular supply. Epidemiology, screening, diagnosis, and treatment interventions are covered as well as basic science, biochemical and immunological studies. The manuscript management system is completely online and includes a very quick and fair peer-review system, which is all easy to use. Visit http://www.dovepress.com/testimonials.php to read real quotes from published authors. 